\title{
Dental Implants and General Dental Practitioners of Nepal: A study of existing knowledge and need for further education
}

\author{
Bhageshwar Dhami $^{1}$, Priti Shrestha ${ }^{2}$, Bikash Lamichhane ${ }^{3}$, Anuj Kumar Sharma ${ }^{3}$, Sujaya Gupta ${ }^{4}$ \\ ${ }^{1}$ Asst Prof, ${ }^{4}$ Lecturer, Dept. of Periodontics, Kantipur Dental College, Kathmandu, Nepal \\ ${ }^{2}$ Lecturer, Dept. of Periodontics, Kist Medical College, Kathmandu, Nepal \\ ${ }^{3}$ Dental Surgeon, Kathmandu, Nepal
}

\section{Correspondence}

Dr. Bhageshwar Dhami,

Department of Periodontics,

Kantipur Dental

College,Teaching Hospital

and Research Center,

Kathmandu, Nepal

\section{Email:}

dhamibhagesh@hotmail.com

DOI: http://dx.doi.org/10.3126/ jemsn.v13i1.16668

Article received: Dec $11^{\text {th }} 2016$ Article accepted: Feb $2^{\text {nd }} 2017$

\begin{abstract}
Background \& Objectives: The use of dental implants in partially or completely edentulous patients has proved effective and an accepted treatment modality with predictable long-term success. Dental implants are becoming a popular choice for replacing the missing teeth because of increased awareness about implants both in dentists and patients. The objective of the study was to assess the basic knowledge and education about dental implants among general dental practitioners (GDPs) of Nepal. Materials \& Methods: A cross sectional questionnaire was carried out among 110 GDPs which consist of twenty questions that were divided into three categories; first with some basic knowledge in implant dentistry, second with clinical knowledge of dental implants and third with dental implant education and training. Results: Out of 110 GDPs, $72.7 \%$ had basic knowledge about implant dentistry and $65.5 \%$ were not aware about advance surgical procedures like sinus lift and guided bone regeneration. All the GDPs were positive regarding more training and education in dental implants and $95.5 \%$ of them would like to incorporate dental implant treatment in their practice in future. Conclusion: GDPs should have adequate knowledge and training of dental implants which can be incorporated at undergraduate or post doctoral level so that they are skilled to provide quality dental implant therapy to their patients confidently.
\end{abstract}

Key words: Dental implants; education; general dental practitioner; knowledge

Citation: Dhami B, Shrestha P, Lamichhane B, Sharma AK, Gupta S. Dental Implants and General Dental Practitioners of Nepal: A study of existing knowledge and need for further education. JCMS Nepal. 2017;13(1):212-5.

\section{INTRODUCTION}

The use of dental implants in the rehabilitation of partially or completely edentulous patients has become a well established and accepted treatment modality with predictable long term success. ${ }^{1,2}$ Recent advances in implant designs, graft materials and surgical protocols have played a significant role in making implant as predictable treatment option. Thus, dental implant is becoming a popular choice in the replacement of missing teeth.

Use of dental implants over the last decade has increased mainly because of increased awareness about dental implants both in dentists and patients. Nowadays, it is common to see a patient walking into a practice with already implant being placed in $\mathrm{him} / \mathrm{her}$ or asking for implant placement. Furthermore, dental implant sales continue to rise in developed countries ${ }^{3-5}$ and as public awareness and demands increase, many more general dental practitioners (GDPs) will certainly want to provide dental implant treatment. Therefore, it has become compulsory for the GDPs to be well-acquainted with dental implants.

Dental implant education surveys specifically of GDPs have not been conducted and published in Nepal. Internationally, there has been some research and comment related to dental implant education and GDPs. ${ }^{6-10}$ This study aims to assess the basic 
knowledge and education about dental implants among GDPs of Nepal.

\section{MATERIALS AND METHODS}

A cross sectional questionnaire was carried out among 110 GDPs from June 2016 to September 2016. The study was conducted after receiving approval from Institutional Review Committee of Kantipur Deptal College. GDPs practicing in Kathmandu, Nepal were the chosen population for the study. Twenty questions were formatted for this study that were divided into three categories; first with some basic knowledge in implant dentistry, second with clinical knowledge of dental implants and third with the dental implant education and training. GDPs were asked to record their responses. This data formed the basis for assessment. Data analysis was done using SPSS version 20 .

\section{RESULTS}

The results are reported by summarizing responses to each of the 20 questions in the study. The first 6 questions were about some basic knowledge in implant dentistry (Table 1), from 7 to 13 questions were regarding clinical knowledge of dental implants (Table 2) and from 14 to 20 questions were regarding dental implant education and training. (Table 3)

On an average, $80(72.7 \%)$ out of 110 GDP had basic knowledge about implant dentistry and $65.5 \%$ were not aware about advance surgical procedures like sinus lift, guided bone regeneration

Table 1: Basic knowledge in Implant Dentistry

\begin{tabular}{llll} 
& \multicolumn{1}{c}{ Questions } & Yes(\%) & No(\%) \\
\hline 1 & Dental implant awareness & $110(100)$ & 0 \\
2 & Various parts of dental implants & $100(90.9)$ & $10(9.1)$ \\
3 & Types of dental implant & $67(60.9)$ & $43(39.1)$ \\
\hline 4 & Various systems of dental implant & $74(67.3)$ & $36(32.7)$ \\
\hline 5 & Various surgical techniques of dental implant placement & $63(57.3)$ & $47(42.7)$ \\
& $\begin{array}{l}\text { Distance between 2 implants } \\
\text { Distance between implant and natural tooth }\end{array}$ & $67(60.9)$ & $43(39.1)$ \\
& $\begin{array}{l}\text { Distance of implant from anatomic structures i.e. maxillary } \\
\text { sinus, inferior alveolar canal, mental foramen etc }\end{array}$ & $86(78.1)$ & $34(30.9)$ \\
6 & $\begin{array}{l}\text { Dental implant placement in Smokers, Diabetes, Periodontal } \\
\text { disease }\end{array}$ & $76(69.1)$ & $34(30.9)$ \\
& &
\end{tabular}

Table 2: Clinical knowledge of Dental Implants

\begin{tabular}{|c|c|c|c|}
\hline & Questions & Yes $(\%)$ & $\mathrm{No}(\%)$ \\
\hline 7 & Aware of advance surgical procedures like GBR, sinus lift etc & $38(34.5)$ & $72(65.5)$ \\
\hline 8 & Aware of immediate and delayed implant placement & $28(25.5)$ & $82(74.5)$ \\
\hline 9 & $\begin{array}{l}\text { Aware of loading protocols such as immediate, early and } \\
\text { delayed loading }\end{array}$ & $27(24.5)$ & $83(75.5)$ \\
\hline 10 & Aware about peri-implant disease & $34(30.9)$ & $76(69.1)$ \\
\hline 11 & Dental implant placement in their practice & $10(9.1)$ & $100(90.9)$ \\
\hline 12 & Treatment option about dental implant to patient & $98(89.1)$ & $12(10.9)$ \\
\hline 13 & $\begin{array}{l}\text { Difficulty of dental implant placement compared to other } \\
\text { treatment option } \\
\text { If Yes, difficulty is related to } \\
\text { skill } \\
\text { instruments and materials } \\
\text { high cost } \\
\text { unpredictable success }\end{array}$ & $\begin{array}{l}46(56.8) \\
24(29.6) \\
28(34.6) \\
13(16)\end{array}$ & $29(26.4)$ \\
\hline
\end{tabular}


Table 3: Dental Implant Education

\begin{tabular}{llll}
\multicolumn{1}{c}{ Questions } & Yes(\%) & No(\%) \\
14 & Former education in implant dentistry & $20(18.2)$ & $90(81.8)$ \\
15 & Satisfaction of dental implant education at undergraduate level & $19(17.3)$ & $91(82.7)$ \\
16 & Need for training and education in dental implant & $110(100)$ & $0(0)$ \\
17 & Incorporation of dental implant treatment in future practice & $105(95.5)$ & $5(4.5)$ \\
18 & Implant education and training best at & & \\
$\quad$ & Undergraduate level & $43(39.1)$ & \\
19 & Post doctoral level & $67(60.9)$ & \\
$\quad$ Best method for dental implant education and training & $6(5.5)$ & \\
$\quad$ Few days training & $38(34.5)$ & \\
$\quad$ Six months training & $42(38.2)$ & \\
$\quad$ One year training & $24(21.8)$ & \\
$\quad$ Three years MDS & $99(90)$ \\
& Restoration of your first molar if missing, with & $10(9.1)$ & \\
$\quad$ Dental Implant & $1(0.9)$ & $0(0)$
\end{tabular}

etc., for dental implant surgery. Amongst all GDPs, $75 \%$ were not aware about immediate and delayed implant placement and about loading protocols such as immediate, early and delayed loading, $76 \%$ of GDPs were not aware about peri-implant disease and $81 \%$ of them found dental implant placement difficult compared to other treatment options mainly because of difficulty related to skill and high cost. Only $9.1 \%$ had undergone formal education and training in dental implant while $82.7 \%$ were not satisfied with dental implant education at undergraduate level and $60.9 \%$ thought dental implant education and training is best at post doctoral level after attaining minimum skills required to practice dental implants. All the GDPs were positive regarding more training and education in dental implants, out of which $38.2 \%$ would like to have one year training followed by $34.5 \%$ for six months training and $95.5 \%$ of them would like to incorporate dental implant treatment in their practice in future. In this study, $90 \%$ of them would like to replace their first molar with dental implant, 9.1\% would like replace with crown and bridge and $0.9 \%$ with removable partial denture.

\section{DISCUSSION}

In this study, though only 110 GDPs of Kathmandu, Nepal were included to evaluate knowledge and education of dental implant, this study gives an opinion of relevant group of GDPs. All GDPs should have adequate knowledge regarding diagnosis and treatment of dental implant placement as dental implant therapy has become an integral part of dental practice. As the number of patients with dental implant increases, more GDPs will be dealing with implant monitoring and maintenance issues. If large numbers of GDPs do not gain the necessary knowledge to provide implant maintenance then problems may occur. GDPs should have the basic skill to maintain these implants and recognize associated pathology. In cases of periimplantitis, they should have knowledge regarding suitable interventions. ${ }^{11}$ The monitoring and maintenance of those implants may fall upon GDPs. ${ }^{12}$

Fortunately, a vast majority of the GDPs surveyed thought that they, at least, have a role in educating patients about dental implants and in suggesting the option of dental implants to patients where appropriate. This finding reflects an understanding of professional responsibility towards specific patients and the dental health of the community in general. They should also be able to differentiate between low, medium, and high risk patients and also be able to know when to refer the patient to specialists.

In this study, majority of GDPs had basic knowledge of dental implant, however, only few are practicing dental implants, that could be because most of them had not undergone any kind of formal dental implant training and majority of them thought dental implant treatment is more difficult than other treatment options because of intricate 
skill required and high cost. Almost all GDPs want to have training and education in dental implants so that they can incorporate implant treatment in their future practice.

Majority of GDPs thought that implant education and training is best at post-doctoral level after attaining minimum skills required to practice dental implant treatment and majority of them thought one year dental implant education and training is sufficient to practice dental implant. However, it is a matter of discussion whether we can include more basics with theoretical and practical aspects of dental implant at an undergraduate level in their curriculum as recommendation made by various authors in the literature. ${ }^{13-17}$ In order to prepare students to practice dental implants into their private practice, dental colleges need to incorporate a combination of clinical and laboratory trainings in dental implants at undergraduate programs.

A further study of a broader population of GDPs would be beneficial and may contribute to dental implant education, practice and regulation.

\section{CONCLUSION}

Implant dentistry is growing and gaining wide acceptance as a treatment option for patients with missing teeth. The GDPs have a prominent role as evaluator, clinician and educator. GDPs should have adequate knowledge and training in the field of dental implant which can be incorporated at undergraduate or post doctoral level. This is achieved by employing skills with proper training and education that is required to ensure function, esthetics and longevity to the dental implant supported prosthesis.

\section{REFERENCES}

1. Lekholm U, Gunne J, Henry P, Higuchi K, Lindén U, Bergström C, et al. Survival of the Brånemark implant in partially edentulous jaws: A 10 year prospective multicenter study. Int $J$ Oral Maxillofac Implants. 1999;14:639-45. PMID: 10531735.

2. Weber HP, Sukotjo C. Does the type of implant prosthesis affect outcomes in the partially edentulous patient? Int J Oral Maxillofac Implants. 2007;22 Suppl:140-72. PMID: 18437795.

3. US Markets for Dental Implants. Executive Summary. Implant Dent. 2003;12:108-11.

4. Japanese Markets for Dental Implants. Annual Industry Report. Implant Dent. 2003;12:272-4. DOI: 10.1097/01.ID.0000091124.99510.A7.

5. European Markets for Dental Implants. Annual Industry Report. Implant Dent. 2003;12:268-71. DOI: 10.1097/01.ID.0000091138.99536.FB.

6. Klugman R, Sgan-Cohen H, Stern N. A survey of dentists practicing implant dentistry in Israel. J Prosthet Dent. 1990;64:473-8. DOI: 10.1016/0022-3913(90)90047-G.

7. Brandt RL, Fitzpatrick BJ, Moloney FB, Bartold PM.
Continuing dental education in osseointegrated implants. A survey. Aust Dent J. 2000;45:285-8. DOI: 10.1111/j.18347819.2000.tb00266.x. PMID: 11225533.

8. Payant L, Williams JE, Zwemer JD. Survey of Dental Implant Practice. J Oral Implantol. 1994;20:50-8. PMIID: 7932856.

9. Christensen GJ. Implants and general practitioners. J Am Dent Assoc. 2000;131:359-61. DOI: 10.14219/ jada.archive.2000.0179. PMID: 10715927.

10. Caplanis N, Kan JY, Lozada JL. Implant dentistry education for the practicing dentist. J Calif Dent Assoc. 2001;29:757-64. PMID: 11806054.

11. Hicklin SP, Albrektsson T. Theoretical knowledge in implant dentistry for undergraduate students. Eur J Dent Educ. 2009;13:25-35. DOI: $10.1111 / \mathrm{j} .1600-$ 0579.2008.00553.x. PMID: 19281512.

12. Young MP, Carter DH, Sloan P, Quayle AA. A survey of oral implantology teaching in the university dental hospitals and schools of the United Kingdom and Eire. Br Dent J. 1999;187:671-5. DOI: 10.1038/sj.bdj.4800364. PMID: 10654443.

13. Afsharzand Z, Lim MV, Rashedi B, Petropoulos VC. Predoctoral implant dentistry curriculum survey: European Dental Schools. Eur J Dent Educ. 2005;9:37-45. DOI: 10.1111/j.1600-0579.2004.00363.x. PMID: 15642022.

14. Aljohani HA, AlGhamdi AS. Predoctoral dental implant education at King Abdulaziz University. Saudi Dent J. 2009;21:135-8. DOI: 10.1016/j.sdentj.2009.10.005. PMID: 23960472.

15. Lim MV, Afsharzand Z, Rashedi B, Petropoulos VC. Predoctoral implant education in US Dental Schools. J Prosthdont. 2005;14:46-56. DOI: 10.1111/j.1532849X.2004.04047.x. PMID: 15733135.

16. Weintraub AM, Seckinger R, Berthold P, Weintraub GS. Predoctoral implant dentistry programs in US dental schools. J Prosthodont. 1995;4:116-21. DOI: 10.1111/ j.1532-849X.1995.tb00326.x. PMID: 8528440.

17. Seckinger RJ, Weintraub AM, Berthold P, Weintraub GS. The status of undergraduate implant education in dental schools outside the United States. Implant Dent. 1995;4:105-9. DOI: 10.1097/00008505-199505000-00005. PMID: 7581232. 